\title{
Taxonomia, análise cladística e descrição de uma espécie nova de Palpibracus Rondani (Diptera, Muscidae)
}

\author{
Elaine Della Giustina Soares ${ }^{1} \&$ Claudio José Barros de Carvalho ${ }^{1,2}$
}

\begin{abstract}
${ }^{1}$ Departamento de Zoologia, Universidade Federal do Paraná, Caixa Postal, 19020, 81.531-980 Curitiba-PR, Brasil. Bolsista do CNPq. ${ }^{2}$ cjbcarva@ufpr.br

ABSTRACT. Taxonomy, cladistics analysis and description of a new species of Palpibracus Rondani (Diptera, Muscidae). Palpibracus Rondani is a Muscidae genus with 16 species, including $P$. darwini sp. nov. described from male specimens from Concepción, Chile. A cladistic analysis was performed based on 31 adult morphological characters and using 12 species as outgroup. This analysis shows Palpibracus as a monophyletic genus whose sister-group is Brachygasterina Malloch. The relationship among Palpibracus species was: (P. veneris ((P. albuquerquei (P. peruvianus, P. trivittatus $))$ (P. fasciculatus, $P$. nigriventris)) (( $P$. spicatus, $P$. uvivittatus) (P. lancifer ( $P$. darwini sp. nov. (P. chilensis, $P$. confusus $(P$. pilosus (P. similis (P. separatus, $P$. carvalhoi $)))))))$ ). Palpibracus apicalis Malloch was placed tentatively in Psilochaeta Stein. A key to species of Palpibracus is also provided.
\end{abstract}

KEYWORDS. Key to species, phylogenetic analysis, systematics.

RESUMO. Taxonomia, análise cladística e descrição de uma nova espécie de Palpibracus Rondani (Diptera, Muscidae). Palpibracus Rondani é um gênero de Muscidae que aloca 16 espécies, incluindo Palpibracus darwini sp. nov., descrita com base em espécimens macho de Concepción, Chile. Foi realizada uma análise cladística baseada em 31 caracteres morfológicos de adultos e utilizando 12 espécies como grupos externos. A análise mostrou que Palpibracus é um gênero monofilético cujo grupo-irmão é o gênero Brachygasterina. O relacionamento entre as espécies foi: $(P$. veneris $((P$. albuquerquei (P. peruvianus, P. trivittatus)) (P. fasciculatus, P. nigriventris $))((P$. spicatus, $P$. uvivittatus $)(P$. lancifer $(P$. darwini sp. nov. (P. chilensis, P. confusus (P. pilosus ( P. similis (P. separatus, P. carvalhoi)))))))). Palpibracus apicalis Malloch foi alocada tentativamente em Psilochaeta Stein. É apresentada também uma chave para as espécies de Palpibracus.

PALAVRAS-CHAVE. Análise filogenética, chave para espécies, sistemática.

Palpibracus Rondani, 1863 é um gênero de Muscidae de distribuição restrita ao Chile e região ocidental da Argentina, ao sul do paralelo $30^{\circ} \mathrm{S}$ (Carvalho \& Couri 2002, Carvalho et al. 2003). O gênero está alocado na tribo Reinwardtiini, Azeliinae por apresentar haustelo com esclerotinização ciliada, tergito VI esclerotinizado em forma de âncora e esternito VIII inteiro (Carvalho 1989c). Carvalho (1989c) não encontrou nenhuma sinapomorfia para o gênero Palpibracus nem definiu seu relacionamento com os demais gêneros de Reinwardtiini, entretanto o autor já havia sugerido que o gênero fosse provavelmente monofilético (Carvalho 1989a).

Palpibracus foi descrito sob o nome Brachypalpus Macquart para acomodar Brachypalpus pilosus (Macquart, 1851). Porém, uma vez que Brachypalpus já havia sido utilizado anteriormente, Rondani (1863) alterou o nome para Palpibracus. Este gênero permaneceu monotípico até que Albuquerque (1951) propôs a sinonímia de Darwinomyia Malloch em Palpibracus Rondani. Darwinomyia havia sido proposto por Malloch $(1922$, ver também 1928, 1934) que até 1934, já havia descrito 11 espécies: Palpibracus confusus (Malloch, 1922), Palpibracus nigriventris (Malloch, 1928), Palpibracus angolensis (Malloch, 1934), Palpibracus apicalis (Malloch, 1934), Palpibracus fasciculatus (Malloch, 1934), Palpibracus lancifer (Malloch, 1934), Palpibracus reynoldsi (Malloch, 1934), Palpibracus separatus (Malloch, 1934),
Palpibracus similis (Malloch, 1934), Palpibracus spicatus (Malloch, 1934) e Palpibracus trivittatus (Malloch, 1934). Além destas, três espécies descritas por J.M.F. Bigot foram alocadas no gênero: Palpibracus chilensis (Bigot, 1885), Palpibracus univittatus (Bigot, 1857) e Palpibracus veneris (Bigot, 1888). Albuquerque (1951) descreveu Palpibracus subtilis, que posteriormente foi sinonimizada em P. separatus (Albuquerque 1979). Ao realizar a revisão do gênero, Carvalho (1989a) propôs a combinação de Phaonia peruviana Malloch, 1929 em Palpibracus e sinonimizou Palpibracus angolensis com esta espécie, além de descrever Palpibracus albuquerquei. Carvalho et al. (1993) sinonimizaram P. reynoldsi em P. pilosus. Lopes \& Khouri (1996) descreveram Palpibracus carvalhoi. Pamplona \& Couri (2000) descreveram Palpibracus valdiviensis que foi transferida por Soares \& Carvalho (2004) para o gênero Brachygasterina Macquart. Esta nova combinação não consta no catálogo mais recente para Muscidae da região Neotropical (Carvalho et al. 2005).

Este trabalho tem como objetivo contribuir para o entendimento da taxonomia de Palpibracus Rondani e compreender a evolução do gênero através da análise cladística baseada na morfologia dos adultos; propõe também uma chave de identificação para todas as espécies do gênero e descreve uma nova espécie para o Chile. 


\section{MATERIAL E MÉTODOS}

O material examinado foi proveniente da Coleção de Entomologia Pe. Jesus Santiago Moure, Departamento de Zoologia, Universidade Federal do Paraná (DZUP), Curitiba, Brasil; Museu Nacional, Universidade Federal do Rio de Janeiro (MNRJ), Rio de Janeiro, Brasil; Museu de Zoologia, Universidade de São Paulo (MZSP), São Paulo, Brasil; The University of Illinois at Chicago, Departament of Biological Sciences, College of Liberal Arts and Sciences (UIC), Illinois, Estados Unidos.

O seguinte material de Palpibracus Rondani foi examinado: exemplares de ambos os sexos de $P$. carvalhoi, $P$. chilensis, $P$. confusus, $P$. nigriventris, $P$. pilosus, $P$. separatus, $P$. spicatus, $P$. trivittatus, $P$. univittatus e $P$. veneris; apenas fêmeas de $P$. fasciculatus e $P$. lancifer e apenas exemplares macho de $P$. albuquerquei, $P$. darwini sp. nov., $P$. peruvianus e $P$. similis. $\mathrm{O}$ palpo de $P$. fasciculatus, a terminália interna de $P$. separatus e a placa cercal de $P$. carvalhoi não puderam ser examinados por estarem ausentes ou destruídos (placa cercal de $P$. carvalhoi) no material disponível. Os dados do material não disponível foram retirados da literatura (Malloch 1934; Carvalho 1989a). A lista de material examinado está apresentada no apêndice. Foram analisados os holótipos de $P$. albuquerquei, $P$. carvalhoi e $B$. valdiviensis.

A terminologia utilizada foi a apresentada por McAlpine (1981) incluindo as modificações feitas por Carvalho (1989a). Foram utilizadas as abreviaturas, referentes à posição das cerdas nas pernas, sugeridas por Carvalho (1989a): A - face anterior; AD - face ântero-dorsal; AV - face ântero-ventral; D - face dorsal; P - face posterior; PD - face póstero-dorsal; PV - face póstero-ventral. A descrição da espécie nova segue o modelo das descrições feitas por Carvalho (1989a) para que a padronização das descrições fosse mantida.

A chave para as espécies de Palpibracus foi baseada no material examinado e nas chaves propostas por Malloch (1934), Carvalho (1989a) e Carvalho \& Couri (2002).

A monofilia foi testada através do método de comparação com o grupo externo (Nixon \& Carpenter 1993). Para a escolha do grupo externo, foi adotada a classificação proposta por Carvalho (1989c). A lista das espécies incluídas no grupo externo está incluída no apêndice.

A análise cladística foi baseada em 31 caracteres de morfologia externa de adultos e de terminália de macho de 28 táxons (Tabela I). Para o enraizamento das árvores, foi escolhida Delia platura (Meigen), uma espécie de Anthomyiidae, família considerada grupo-irmão de Muscidae (Michelsen 1991).

Todos os caracteres foram considerados não aditivos. Os caracteres autapomórficos não foram incluídos na análise. A matriz de dados foi editada através do programa NEXUS versão 0.5.0 (Page 2001). A busca da árvore mais parcimoniosa foi realizada pelo NONA versão 2.0 (Goloboff 1993) utilizando o programa Winclada versão 0.9.9b (Nixon 1999). Foram utilizadas as seguintes opções: busca heurística; "maximum trees to keep"=1000; "number of replications $($ mult*N)"=1000; "starting trees per rep $($ hold $/) "=100$; "random seed"=1224; unconstrained search; e estratégia de busca Multiple TBR

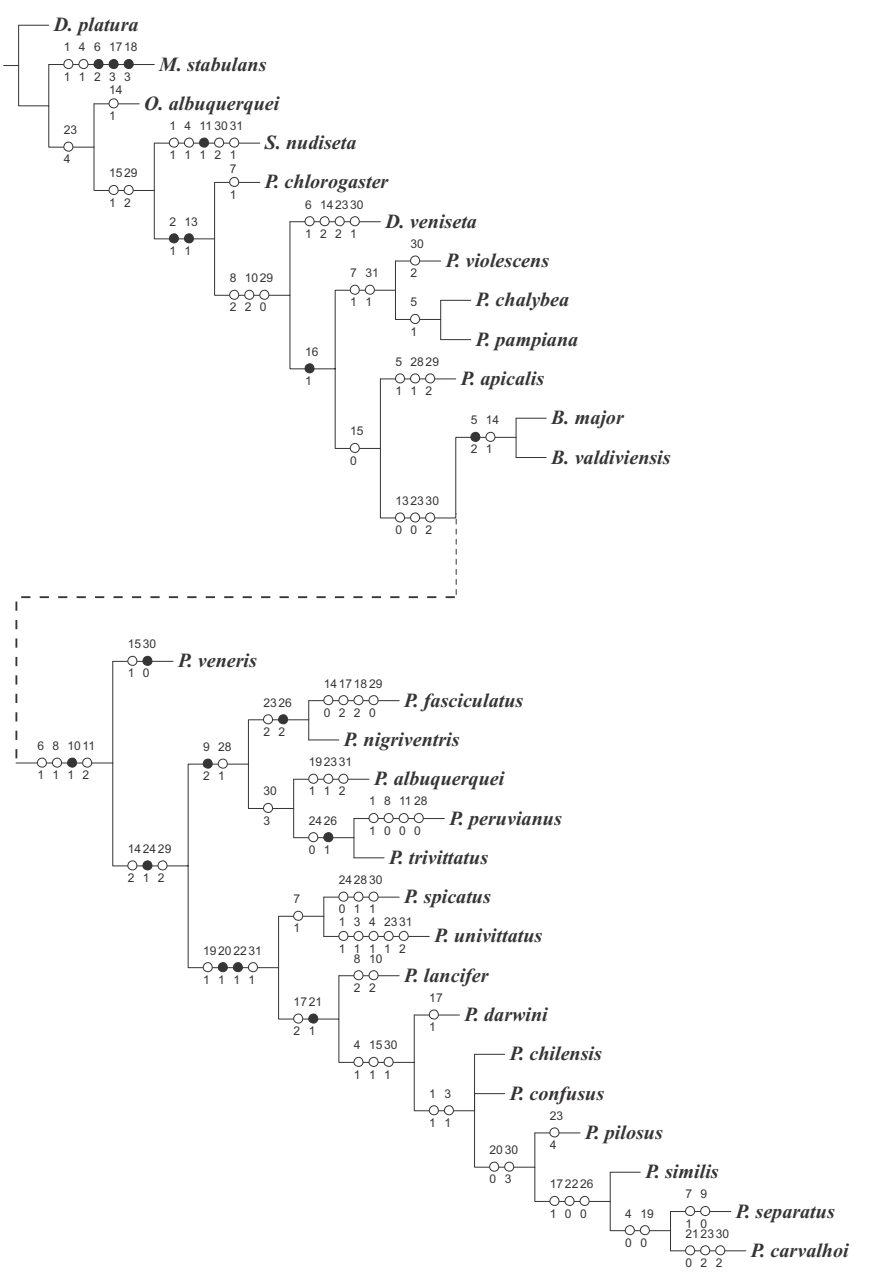

Fig. 1. Cladograma de Palpibracus Rondani apresentando apenas os caracteres não ambíguos. Comprimento 121, índice de consistência 42 índice de retenção 72. As sinapomorfias estão representadas pelos círculos negros e as homoplasias pelos brancos.

("default" do programa). No cladograma (fig. 1) estão apresentados apenas os caracteres não ambíguos.

\section{Taxonomia \\ Palpibracus Rondani, 1863}

Espécie tipo: Brachypalpus pilosus Macquart, 1851.

Diagnose: Olhos ciliados; macho holóptico; arista com cílios de tamanho igual ou menor que o diâmetro da base da arista; cerdas interfrontais da fêmea presentes ou ausentes; cerdas acrosticais pré-suturais desenvolvidas; pré-alar forte; notopleura sem cílios de revestimento e com a notopleural posterior mais curta que a anterior; catepímero com ou sem cílios; asa com veias nuas; calcar presente; abdôme oval. Fêmea com ovipositor longo e tubular; tergito VI esclerotinizado em forma de âncora; tergito VII estreito; exceto em P. veneris, esternito VI e VII divididos posteriormente, exceto em $P$. lancifer; esternito VIII desenvolvido em toda a extensão, mais esclerotinizado na região posterior; hipoprocto alongado; três espermatecas piriformes. 

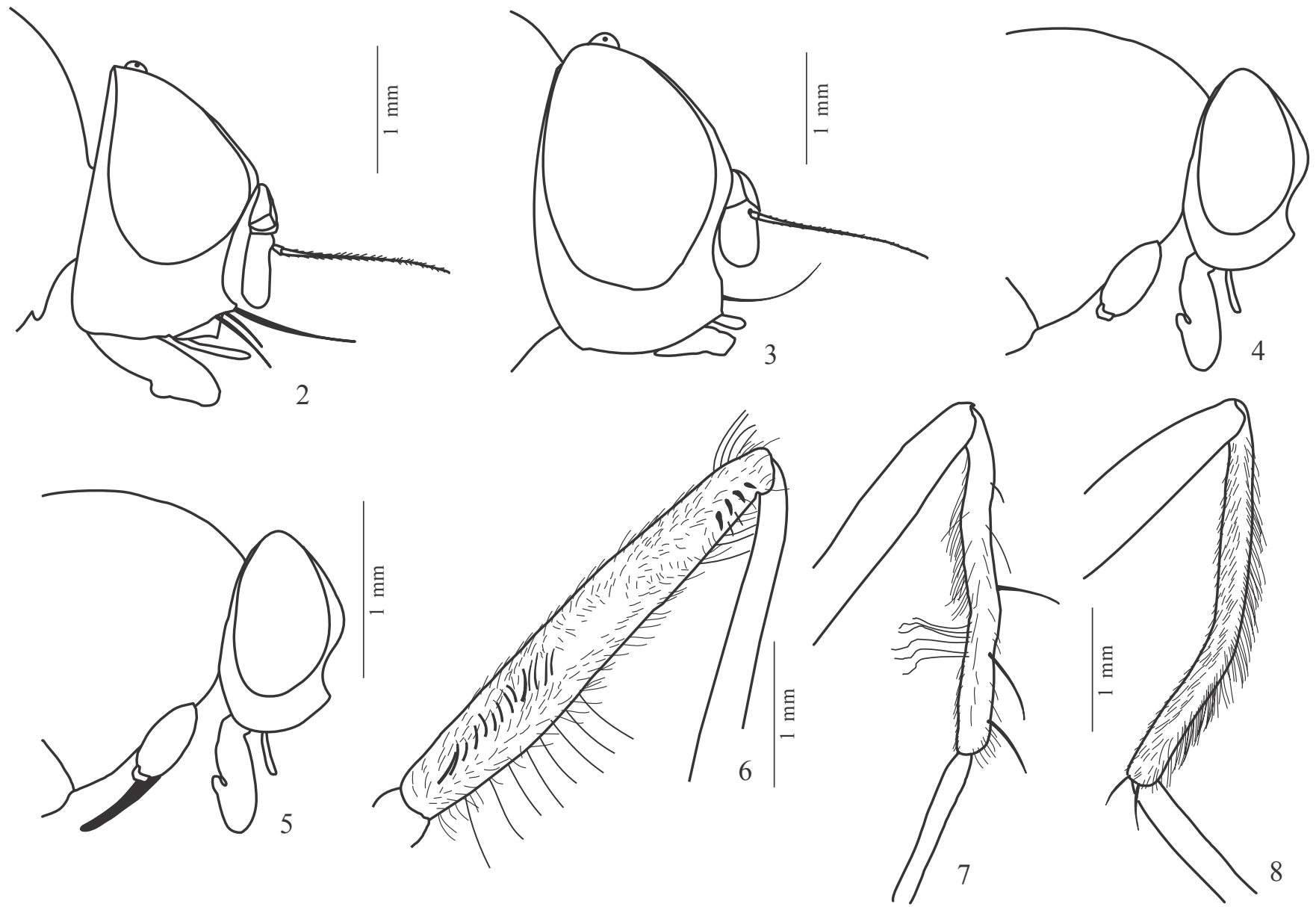

Figs. 2-8. 2, Antena de Palpibracus veneris (Bigot), macho, vista lateral; 3, Antena de Brachygasterina major Malloch, macho, vista lateral; 4 , Esquema da coxa anterior do macho sem esporão apical, vista lateral; 5, Esquema da coxa anterior do macho mostrando o esporão apical, vista lateral; 6, Fêmur médio do macho de Palpibracus darwini sp. nov., vista anterior; 7, Tíbia posterior de macho de Palpibracus nigriventris (Malloch), vista anterior; 8, Tíbia posterior de $P$. darwini sp. nov. macho, vista posterior. As figuras não estão na mesma escala.

Fêmea com quetotaxia reduzida, como ocorre na maioria dos Muscidae. Macho e fêmea raramente apresentam a quetotaxia simétrica.

Monofilia. O gênero Palpibracus Rondani é monofilético, como havia sido sugerido por Carvalho (1989a). Sua monofilia é sustentada pela presença de (1) mesonoto dorsalmente amarelo com uma listra mediana marrom geralmente regular, que pode estar acompanhada de manchas acessórias; (2) mesoescutelo amarelo. Porém P. peruvianus, $P$. pilosus e $P$. similis apresentam a coloração do tórax mais extensamente marrom e Palpibracus lancifer apresenta tórax e escutelo azul metálico.

Chave para as espécies de Palpibracus Rondani

1. Coloração geral azul metálica, escutelo azul metálico. Macho com esporão apical na coxa anterior formado por pela fusão de duas cerdas longas e fortes (fig. 5); tíbia posterior curva (fig. 8). Fêmea com cerdas interfrontais e com duas cerdas apicais fortes e unidas na coxa anterior. Chile (Osorno); Argentina (Rio Negro) P. lancifer (Malloch)

Coloração geral marrom ou amarela com listra dorsal marrom no mesonoto (figs. 9-11), esta listra pode estar acompanhada por manchas irregulares marrons; escutelo amarelo. Macho com esporão apical na coxa anterior ausente ou presente (figs. 4-5); tíbia posterior reta, curva ou sinuosa (figs. 8-7). Fêmea com ou sem cerdas interfrontais e com as cerdas apicais da coxa anterior não conspícuas

2(1). Mesonoto dorsalmente marrom, ou no mínimo com uma listra marrom dorsal que se estende até as cerdas intraalares; lateralmente, ao menos anepisterno, anepímero e méron marrons. Fêmea com cerdas interfrontais ..... 3

Mesonoto amarelo com listra dorsal marrom não atingindo as cerdas intra-alares. Fêmea: cerdas interfrontais presentes ou ausentes

3 (2). Catepímero nu; palpo amarelo. Macho: esporão apical na coxa anterior ausente (fig. 4). Chile (Bio Bio, Curicó, Malleco, Perales); Argentina (Rio Negro) .....

P. peruvianus(Malloch)

Catepímero ciliado; palpo marrom ou amarelo. Macho: esporão apical na coxa anterior presente (fig. 5) ...... 4 

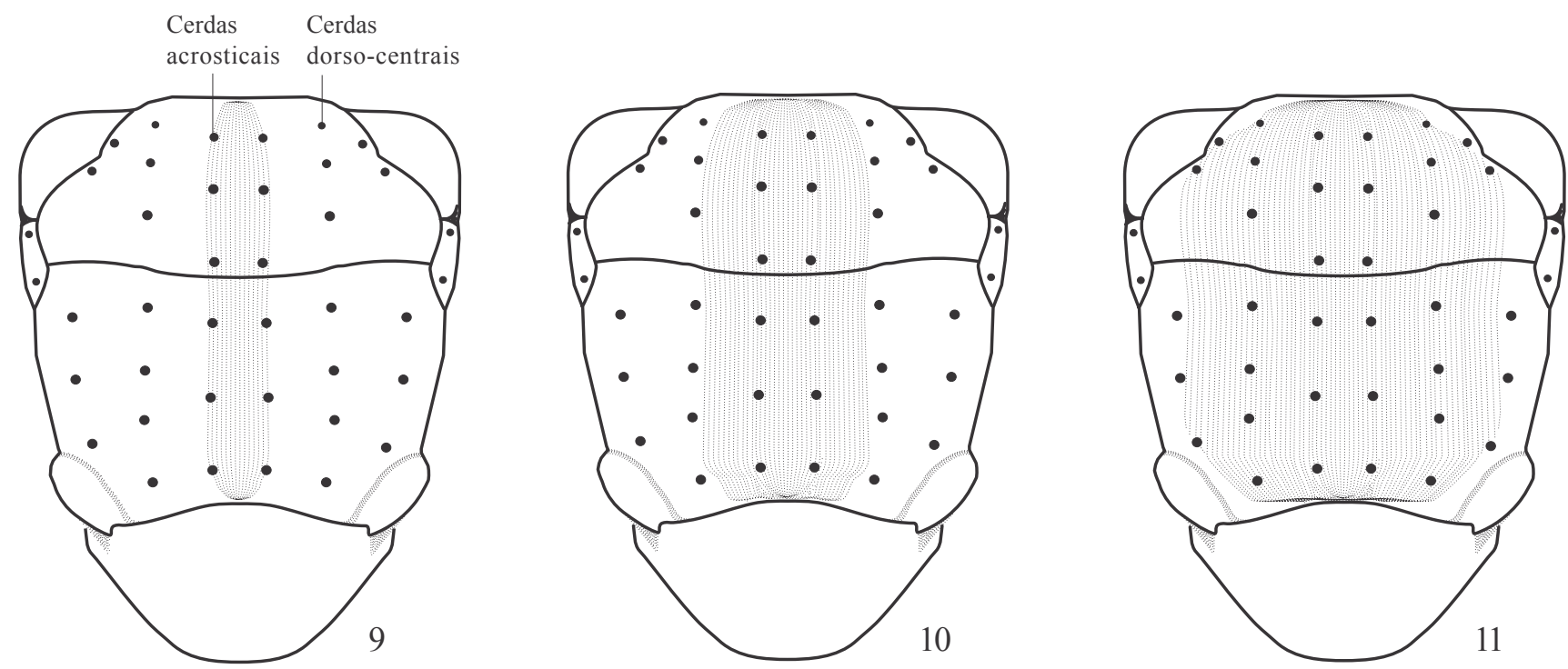

Figs. 9-11. Esquema do padrão de coloração do mesonoto das espécies com coloração amarela e listra dorsal marrom, vista dorsal, modificado de McAlpine (1981). 9, Listra mediana estreita (atingindo no máximo as acrosticais); 10, Listra dorsal média, estendendo-se além das acrosticais, sem atingir as dorso-centrais; 11, Listra dorsal larga, se estendendo sobre as dorso-centrais ou além destas.

4(3). Notopleura, margem do tórax e parede pós-alar amarelas. Macho: fêmur médio com uma fileira de cerdas fortes na metade basal da face póstero-ventral (fig. 6); tíbia posterior curva. Chile (Magallanes); Argentina (Santa Cruz, Terra do Fogo) P. pilosus (Macquart)

Notopleura, margem do tórax e parede pós-alar marrons. Macho: fêmur médio com 3-4 cerdas fortes na metade basal da face póstero-ventral, tibia posterior curva (fig. 8). Chile (Nuble); Argentina (Neuquén, Rio Negro) ....... P. similis (Malloch)

5 (2). Catepímero ciliado 6

Catepímero nu

6(5). Esternito I ciliado. Macho: sem esporão apical na coxa anterior (fig. 4) e sem espinhos e cerdas modificadas na face anterior do fêmur médio. Chile (Malleco) ....... P. carvalhoi Lopes \& Khouri, 1996

Esternito I nu. Macho: esporão apical na coxa anterior, espinhos e cerdas modificadas na face anterior do fêmur médio presentes (fig. 6) ou ausentes ................ 7

7 (6). Cerdas catepisternais 1:2; tíbia média sem cerdas na face póstero-ventral; palpo e antena marrons. Macho: coxa anterior sem esporão apical (fig. 4); fêmur médio sem depressão mediana e sem espinhos curtos no terço apical da face anterior; tíbia posterior reta. Fêmea: cerda interfrontal presente. Chile (Chiloé, Llanquihue, Magallanes, Nuble); Argentina (Rio Negro, Terra do Fogo) P. veneris (Bigot)

Cerdas catepisternais $1: 3$; tíbia média com uma ou mais cerdas na face póstero-ventral; palpo e antena marrons ou amarelos. Macho: esporão apical da coxa anterior presente ou ausente; femur médio com ou sem cerdas diferenciadas e espinhos curtos na face anterior; tíbia posterior curvada. Fêmea: cerdas interfrontais presentes ou ausentes

8(7). Palpo marrom; mesonoto com listra mediana dorsal marrom estendendo-se além das cerdas acrosticais, mas não atingindo as dorso-centrais (fig. 10). Macho: coxa anterior com esporão apical (fig. 5), fêmur médio com depressão mediana e espinhos curtos no terço apical da face anterior (fig. 6). Fêmea: desconhecida. Chile (Concepción)

P. darwini sp. nov.

Palpo amarelo; listra marrom recobrindo apenas as cerdas acrosticais ou estendendo-se além delas, porém sem atingir as cerdas dorso-centrais (figs. 9-10). Macho: esporão apical da coxa anterior presente ou ausente; fêmur médio, na face anterior, com ou sem depresão mediana e espinhos curtos no terço apical. Fêmea com ou sem cerdas interfrontais 9

9(8). Listra mediana dorsal marrom recobrindo apenas as cerdas acrosticais (fig. 9). Macho sem esporão apical na coxa anterior (fig. 4); fêmur médio sem depressão mediana e sem espinhos curtos no terço apical da face anterior. Fêmea sem cerdas interfrontais. Chile (Bio Bio, Concepción, Linares, Osorno, Perales, Santiago) P. separatus (Malloch)

Listra mediana dorsal marrom estendendo-se além das cerdas acrosticais, mas não atingindo as cerdas dorsocentrais. Macho com esporão apical na coxa anterior (fig. 5), fêmur médio com depressão mediana e espinhos curtos no terço apical da face anterior (fig. 6). Fêmea com cerdas interfrontais 10 


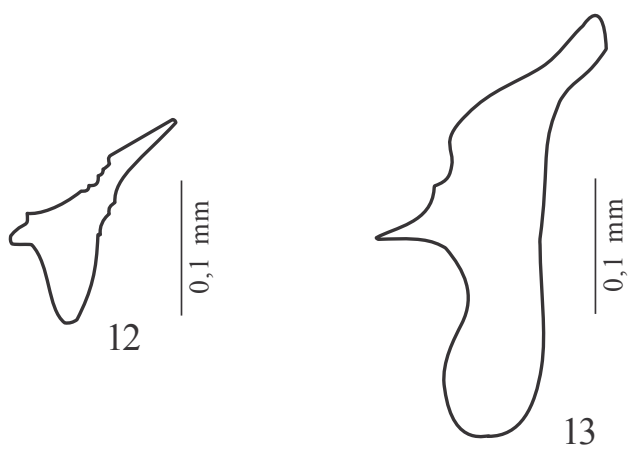

13

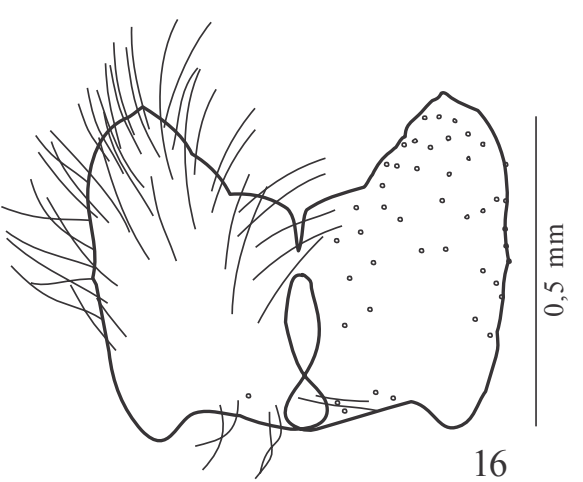

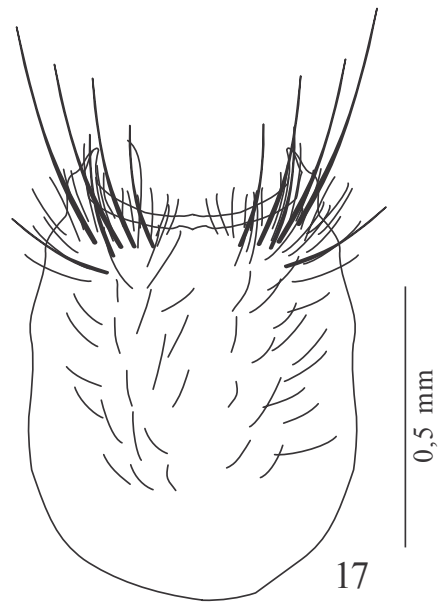
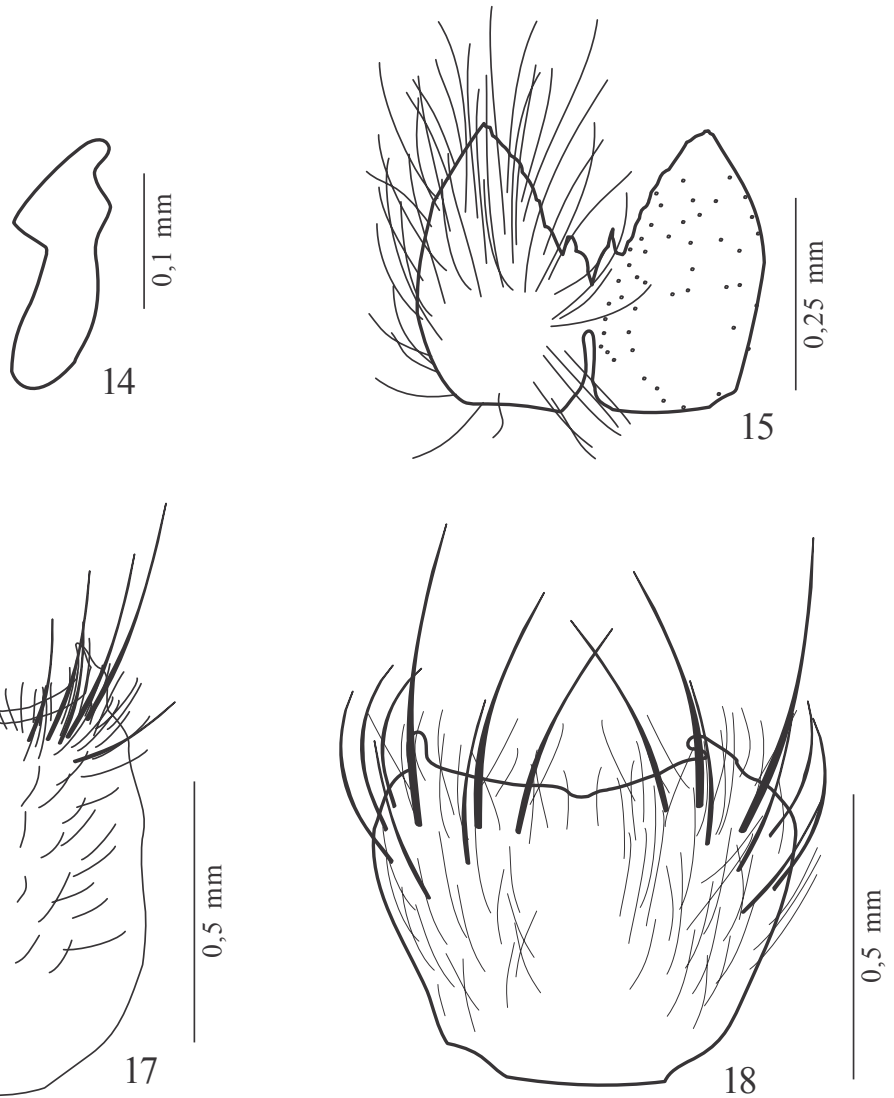

Figs. 12-18. 12, Gonópodo de Psilochaeta chalybea (Weidemann), vista lateral; 13, Gonópodo de Palpibracus albuquerquei Carvalho, vista lateral; 14, Gonópodo de Palpibracus trivitatus (Malloch), vista lateral; 15, Placa cercal de Brachygasterina major Malloch, vista dorsal; 16, Placa cercal de P. albuquerquei, vista dorsal; 17, Quinto esternito de Palpibracus veneris (Bigot), vista dorsal; 18, Quinto esternito de P. albuquerquei, vista ventral. As figuras não estão na mesma escala.

10(9).Pernas amarelas, com no máximo um anel pré-apical marrom; fêmur anterior amarelo. Chile (Curicó, Malleco) P. chilensis (Bigot)

Pernas mais extensamente acastanhadas; fêmur anterior marrom com articulação fêmuro-tibial amarelada. Chile (BioBio, Cautin, Chiloé, Concepción, Curicó, Llanquihue, Malleco, Nuble, Valparaíso); Argentina (Chubut, Ilha Grande, Santa Cruz, Terra do Fogo) ..... P. confusus (Malloch)

11(5).Listra mediana dorsal marrom recobrindo apenas as cerdas acrosticais (fig. 9). Macho: coxa anterior com esporão apical (fig. 5); fêmur médio com depressão mediana e espinhos curtos no terço apical da face anterior (fig. 6). Fêmea: cerdas interfrontais ausentes .

12

Listra mediana dorsal marrom estendendo-se além das cerdas acrosticais (figs. 10-11). Macho: coxa anterior com ou sem esporão apical; fêmur médio sem depressão mediana e sem espinhos curtos no terço apical da face anterior. Fêmea: cerdas interfrontais presentes 13

12(11).Palpo marrom. Macho: Fêmur médio sem cerdas fortes na metade basal da face póstero-ventral; tíbia posterior levemente curva. Chile (Chiloé, Colchagua, Curicó, Llanquihue, Osorno, Santiago); Argentina (Rio Negro) P. spicatus (Malloch)

Palpo amarelo. Macho: Fêmur médio com uma cerda forte na metade basal da face póstero-ventral; tíbia posterior fortemente curva (fig. 8). Chile (Chiloé, Osorno) ........ P. univittatus (Bigot)

13(11).Listra mediana do mesonoto marrom-clara; catepisterno com duas cerdas posteriores. Macho: coxa anterior sem esporão apical; fêmur médio com 2 cerdas fortes na metade basal da face póstero-ventral. Chile (Chiloé); Argentina (Rio Negro, Santa Cruz) ....

P. fasciculatus (Malloch)

Listra mediana do mesonoto marrom-escura; catepisterno com três cerdas posteriores. Macho: esporão apical da coxa anterior ausente ou presente; fêmur médio com número variável de cerdas fortes na metade basal da face póstero-ventral

14(13).Macho: esporão apical da coxa anterior presente (fig. 5); fêmur médio com uma cerda forte na metade basal da face póstero-ventral; tíbia posterior curva (fig. 8). 

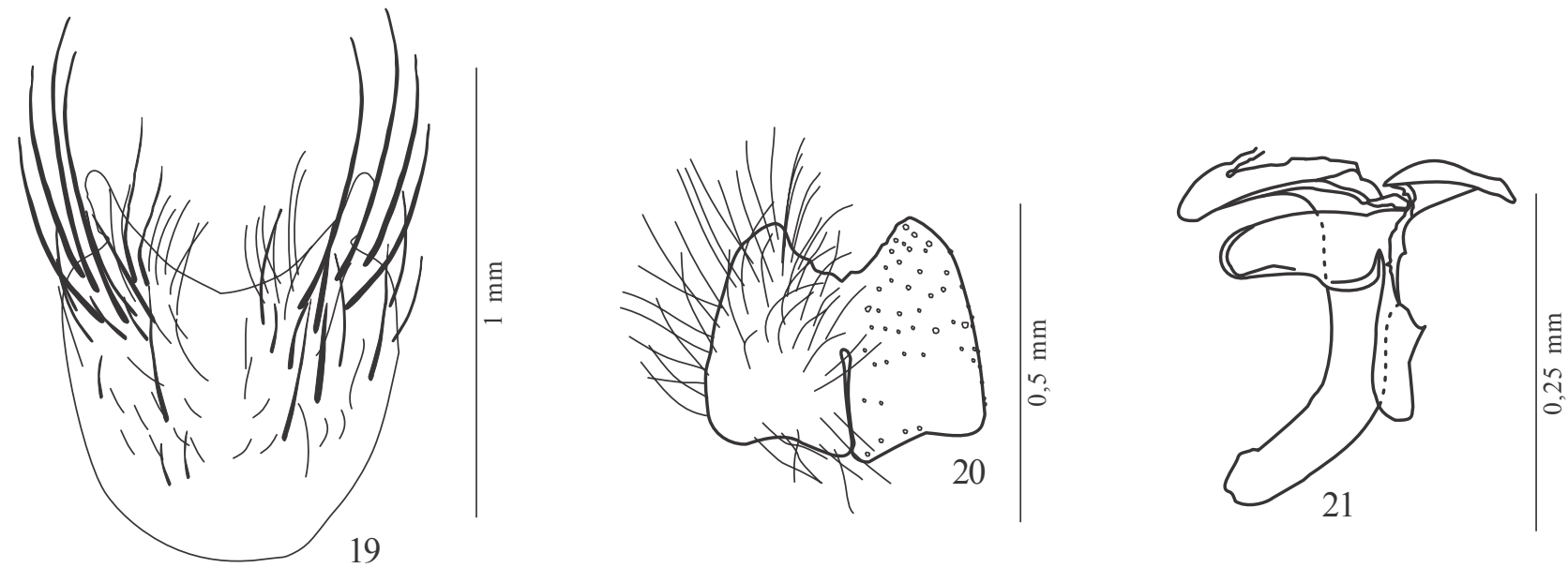

Figs. 19-21. Palpibracus darwini sp. nov. 19, Quinto esternito, vista dorsal; 20, Placa cercal, vista dorsal; 21, edeago, vista lateral. As figuras não estão na mesma escala.

Fêmea: tíbia posterior na face ântero-ventral com 3-5 cerdas na metade apical. Chile (Cautin, Malleco) ........ P. albuquerquei Carvalho, 1989

Macho: esporão apical da coxa anterior ausente (fig. 4); fêmur médio com duas ou nenhuma cerda forte na metade basal da face póstero-ventral; tíbia posterior reta ou sinuosa. Fêmea: tíbia posterior na face ânteroventral com 2-3 cerdas na metade apical

15(14).Listra mediana do mesonoto marrom atingindo as cerdas dorso-centrais, tórax dorsalmente sem manchas acessórias; fêmur médio com 2 cerdas fortes na metade basal da face póstero-ventral; tíbia posterior sinuosa (fig. 7). Chile (Cautin, Chiloé, Curicó, Llanquihue, Magallanes, Malleco); Argentina (Neuquén, Rio Negro, Santa Cruz) ................. P. nigriventris (Malloch)

Listra mediana dorsal marrom estendendo-se além das cerdas dorso-centrais e apresentando-se como três listras separadas ou fundidas; fêmur médio sem cerdas fortes na metade basal da face póstero-ventral; tíbia posterior reta. Chile (Linares, Llanquihue, Malleco); Argentina (Rio Negro) P. trivittatus (Malloch)

\section{Palpibracus darwini sp. nov.}

Macho. Coloração geral amarela com listra marrom mediana dorsal no tórax se estendendo além das acrosticais, mas não atingindo as dorsocentrais. Parafrontália, faciália, parafaciália e gena amarelo-escuras recobertas por polinosidade cinzenta. Lúnula amarelo-alaranjada. Palpo marrom. Antena marrom com base do flagelômero amarela. Escutelo amarelo-claro. Anepisterno com metade basal marrom e metade apical amarela; anepímero marrom; catepisterno e méron amarelos. Calípteras e balancim amarelos. Asa esbranquiçada com as veias marromclaras. Pernas marrons com articulação fêmuro-tibial amarela, terço basal do fêmur médio e posterior amarelo; coxas anterior e posterior marrons, coxa média amarela. Abdome negro.
Olhos fortemente unidos, com numerosos cílios longos, afastados por um espaço que mede, à altura do ocelo anterior, $0,1 \mathrm{~mm}$; facetas ântero-internas desenvolvidas. Cerdas frontais em número de nove pares. Vti semelhante a vte, vti divergente, vte convergente. Antenas inseridas pouco abaixo do nível médio do olho, flagelo medindo cerca de duas vezes o pedicelo. Gena medindo 0,6 mm. Palpo falciforme com cerdas longas na face posterior.

Cerdas dorsocentrais $3: 4$; acrosticais $3: 5 ; 3$ umerais; 2 pósumerais; 1 pré-sutural; 2 intra-alares; 1 pré-alar; 2 supra-alares, a posterior mais fina e curta que a anterior; 2 pós-supra-alares, a posterior mais robusta e 2 vezes mais longa que a anterior. Notopleura sem cílios de revestimento e com 2 cerdas, a posterior mais forte que a anterior. Escutelo com 1 par de cerdas basais fracas, 2 de laterais fortes, 1 de pré-apicais fracas e 1 de apicais fortes. Anepisterno com uma série de 10 cerdas fortes, associadas a cílios diferenciados dos de revestimento na margem posterior e 2 cílios diferenciados no ângulo súperoanterior. Uma cerda pro-episternal e 2 pro-epimerais associadas a cílios longos. Catepisterno 1:3 sem cílios de revestimento diferenciados. Catepímero ciliado, com cílios castanhos. Espiráculo posterior grande, de forma ovóide. Caliptera inferior com o dobro do tamanho da anterior. Asa com as veias $\mathrm{R}_{4+5} \mathrm{e}$ $M_{1+2}$ divergentes para o ápice. Coxa anterior com um esporão apical forte. Fêmur médio (fig. 6) na face A com uma fileira de 5 espinhos fortes no terço apical, uma leve depressão mediana precedida de 2 fileiras irregulares de cerdas fortes com ápice voltado para $\mathrm{D}$ que se iniciam no terço basal e se interrompem na borda da depressão mediana e aumentam de espessura à medida que se aproximam da região mediana; um conjunto de 4 cerdas pré-apicais inseridas obliquamente ao plano longitudinal do fêmur estendendo-se de D para PD, sendo a cerda D a mais fraca; face $\mathrm{V}$ com uma fileira de cerdas fortes eretas no terço basal; PV com 3 cerdas fortes eretas no terço basal e uma fileira de quatro fortes no terço apical. Tíbia média na face $\mathrm{AV}$ com 1 cerda apical forte, faces $\mathrm{D}, \mathrm{AD}, \mathrm{D}, \mathrm{AV}$ e V sem cerdas fortes; face PD com 5 cerdas espaçadas e uma pré apical 
Tabela I. Matriz de dados e lista de caracteres utilizados na análise, mostrando o comprimento do caráter e seus índices de consistência (IC) e retenção (IR). Os dados não comparáveis estão representados na matriz por um hífen "-" e os dados ausentes estão representados por um ponto de interrogação "?".

\begin{tabular}{|c|c|c|c|c|c|c|c|c|c|c|c|c|c|c|c|c|c|c|c|c|c|c|c|c|c|c|c|c|c|c|c|}
\hline & & & & & & & & & & 1 & & & & & & & & & & 2 & & & & & & & & & & 3 & \\
\hline & 1 & 2 & 3 & 4 & 5 & 6 & 7 & 8 & 9 & 0 & 1 & 2 & 3 & 4 & 5 & 6 & 7 & 8 & 9 & 0 & 1 & 2 & 3 & 4 & 5 & 6 & 7 & 8 & 9 & 0 & 1 \\
\hline D.platura & & ( & 0 & 0 & 0 & 0 & 0 & 0 & - & 0 & c & & 0 & ( & 0 & 0 & 0 & 0 & 0 & & 0 & c & 0 & 0 & 0 & - & 0 & - & - & & \\
\hline M.stabulans & & ( & 0 & 1 & 0 & 2 & & 0 & - & 0 & 2 & 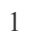 & 0 & ( & 0 & 0 & 3 & 3 & 0 & & 0 & ( & 0 & ( & 0 & - & 0 & 0 & & & \\
\hline O.albuquerqu & & c & 0 & 0 & 0 & 0 & 0 & 0 & - & 0 & 3 & 1 & 0 & 1 & 0 & 0 & 0 & 0 & 0 & & 0 & c & 4 & ( & 0 & - & 0 & 0 & & & \\
\hline S.nu & & c & 0 & 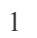 & 0 & 0 & 0 & 0 & - & 0 & 1 & 1 & 0 & ( & 1 & 0 & 0 & 0 & 0 & & 0 & ( & 4 & ( & 0 & - & 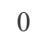 & 0 & & 2 & \\
\hline$D$ & & 1 & 0 & ( & 0 & 1 & 0 & 2 & - & 2 & 3 & 1 & 1 & & 1 & 0 & 0 & & ( & & 0 & ( & & ( & c & - & ? & & & & \\
\hline$B .1$ & & 1 & 0 & 0 & 2 & 0 & 0 & 2 & - & 2 & 3 & 1 & 0 & & c & 1 & ( & & ( & & & ( & & & & - & 1 & & & & \\
\hline$B$. & & 1 & 0 & 0 & 2 & 0 & 0 & 2 & - & 2 & 3 & 1 & 0 & & 0 & 1 & ( & & . & & & & & & & - & & & & & \\
\hline & & 1 & 0 & 0 & 1 & 0 & ( & 2 & - & 2 & 3 & ( & 1 & & c & 1 & ( & & ( & & & ( & & 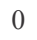 & & 0 & 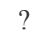 & & & & \\
\hline & & 1 & 0 & 0 & 1 & 0 & & 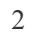 & - & 2 & 3 & . & 1 & & 1 & 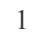 & ( & & & & & & & & & - & 0 & & & & \\
\hline$P$. & & 1 & 0 & 0 & 0 & 0 & & ( & - & ( & 2 & . & 1 & & 1 & ( & ( & & & & & & & & & - & & & & & \\
\hline & & 1 & 0 & 0 & 1 & 0 & 1 & 2 & - & 2 & 3 & . & 1 & & 1 & 1 & & & & & & & & & & - & & & & & \\
\hline & & 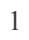 & 0 & 0 & 0 & 0 & & & - & 2 & 3 & & 1 & & & 1 & 0 & & & & & & & & & - & 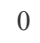 & & & & 1 \\
\hline P.a & & . & 0 & 0 & 0 & 1 & 0 & & 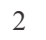 & 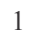 & 2 & ( & 0 & & & 1 & 0 & & & & & & & & & 3 & & & & & \\
\hline P.c & & 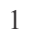 & 1 & 0 & ( & 1 & 0 & & 1 & 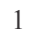 & . & ( & 0 & & & . & & & & & & & & & & 0 & 1 & & & & 1 \\
\hline P.c & & 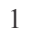 & 1 & 1 & c & 1 & 0 & . & 1 & 1 & 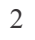 & 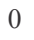 & 0 & & & 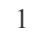 & 2 & & & & & & & & & - & 1 & & & & 1 \\
\hline & & 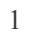 & 1 & 1 & c & 1 & 0 & . & 1 & 1 & . & ( & 0 & & & 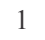 & 2 & & & & & & & & 1 & 3 & 1 & & & & 1 \\
\hline P.d & & 1 & 0 & 1 & 0 & 1 & $?$ & 1 & 1 & 1 & 2 & 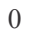 & 0 & 2 & 1 & 1 & 1 & & & & & & & & 1 & 3 & 1 & & & & 1 \\
\hline latus & & 1 & 0 & 0 & ( & 1 & 0 & 1 & 2 & 1 & 2 & c & 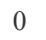 & ( & c & 1 & 2 & & & & & c & & & 1 & 2 & ? & & & & \\
\hline P.lo & ( & 1 & 0 & 0 & ( & 1 & 0 & 2 & - & 2 & 2 & c & 0 & 2 & c & 1 & 2 & & & & 1 & & & & 1 & 3 & $?$ & & & & \\
\hline$P, n$ & ( & 1 & 0 & 0 & 0 & 1 & 0 & 1 & 2 & 1 & 2 & . & 0 & . & ( & 1 & 0 & & & & & & & & 1 & 2 & 1 & & & & \\
\hline P.p & & 1 & 0 & 0 & $?$ & 1 & 0 & 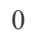 & - & 1 & 0 & ( & 0 & & 0 & 1 & . & & & & & 0 & & & 1 & 1 & 1 & & & & \\
\hline & & 1 & 1 & 1 & 0 & 1 & ( & ( & - & 1 & 2 & ( & 0 & & 1 & 1 & 2 & 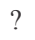 & & & & & & & 1 & 3 & 1 & & & & \\
\hline & & 1 & 1 & 0 & ( & 1 & 1 & 1 & 0 & 1 & 2 & ( & 0 & 2 & 1 & 1 & 1 & 1 & ( & & 1 & ( & & & 1 & 0 & ? & & & & \\
\hline & & 1 & 1 & 1 & ( & 1 & c & ( & - & 1 & 2 & ( & 0 & & 1 & 1 & 1 & & 1 & & & c & & & 1 & 0 & 1 & & & & \\
\hline & & 1 & 0 & 0 & ( & 1 & 1 & 1 & 0 & 1 & 2 & 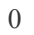 & 0 & & 0 & 1 & 0 & & 1 & & 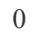 & & & & 1 & 3 & 1 & & & & \\
\hline P.tri & & 1 & 0 & 0 & 0 & 1 & 0 & 1 & 2 & 1 & 2 & 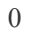 & 0 & & 0 & 1 & 0 & & ( & & 0 & c & & ( & 1 & 1 & 1 & 1 & & & \\
\hline & & 1 & 1 & 1 & 0 & 1 & 1 & 1 & 0 & & 2 & 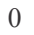 & 0 & 2 & 0 & 1 & 0 & & & & 0 & . & & 1 & 1 & 3 & 1 & 0 & & & \\
\hline P.veneris & 0 & 1 & 0 & 0 & $?$ & 1 & 0 & 1 & 0 & 1 & 2 & 0 & 0 & 0 & 1 & 1 & 0 & 0 & 0 & & 0 & 0 & 0 & 0 & 1 & 3 & 1 & 0 & 0 & 0 & \\
\hline
\end{tabular}

1. Coloração do palpo: [0] marrom; [1] amarela. Comprimento: 5; IC: 20; IR: 55 .

2. Ciliação dos olhos: [0] ausente; [1] presente. Comprimento: 1; IC: 100; IR: 100.

3. Coloração do pedicelo antenal: [0] marrom; [1] amarela. Comprimento: 2; IC: 50; IR: 83 .

4. Coloração do flagelo antenal: [0] marrom; [1] amarela. Comprimento: 5; IC: 20; IR: 42 .

5. Dilatação do flagelo antenal: [0] não dilatado (fig. 2); [1] medianamente dilatado; [2] fortemente dilatado (fig. 3). Comprimento: 3; IC: 66; IR: 66.

6. Tipo de ciliação na arista: [0] pubescente, cílios curtos no terço basal e inconspícuos no ápice da arista (fig. 3); [1] ciliada, cílios conspícuos de tamanho igual ou menor que o diâmetro da arista na base (fig. 2); [2] plumosa, com cílios longos. Comprimento: 3; IC: 66; IR: 88

7. Cerda interfrontal na vita frontal da fêmea: [0] presente; [1] ausente. Comprimento: 4; IC: 25; IR: 50.

8. Coloração geral do tórax: [0] marrom; [1] amarela com listra dorsal marrom; [2] azul metálica. Comprimento: 6; IC: 33; IR: 71.

9. Tipo de listra torácica dorsal marrom: [0] estreita (recobrindo acrosticais); [1] média (estendendo-se além das acrosticais, mas não atingindo as dorsocentrais); [2] larga (recobrindo as dorso-centrais ou estendendo-se além destas). Comprimento: 3; IC: 66; IR: 83.

10. Coloração do escutelo: [0] marrom; [1] amarela; [2] azul metálica. Comprimento: 3; IC: 66; IR: 90.

11. Coloração da caliptera: [0] esbranquiçada; [1] esbranquiçada com borda da caliptera anterior acastanhada; [2] amarelada; [3] acastanhada. Comprimento: 6; IC: 50; IR: 62.

12. Cílios de revestimento na notopleura: [0] ausentes; [1] presentes. Comprimento: 3; IC: 33; IR: 77.

13. Número de cerdas anteriores no catepisterno: [0] uma; [1] duas. Comprimento: 2; IC: 50 ; IR: 80 .

14. Número de cerdas posteriores no catepisterno: [0] duas; [1] uma; [2] três. Comprimento: 5; IC: 40; IR: 72.

15. Ciliação no catepímero: [0] ausente; [1] presente. Comprimento: 4; IC: 25; IR: 76.

16. Ciliação no esternito I: [0] presente; [1] ausente. Comprimento: 1; IC: 100; IR: 100.

17. Coloração do fêmus médio: [0] marrom; [1] metade basal amarela e apical marrom; [2] amarela; [3] base marrom e ápice amarelo. Comprimento: 5; IC: 60; IR: 71.
18. Coloração do fêmur posterior: [0] marrom; [1] metade basal amarela e apical marrom; [2] amarela; [3] marrom com ápice amarelo. Comprimento: 4; IC: 75; IR: 83.

19. Esporão apical na coxa anterior do macho: [0] ausente (fig. 4); [1] presente (um esporão bem definido ou duas cerdas grandes próximas, fig. 5). Comprimento: 3; IC: 33; IR: 75.

20. Depressão mediana na face anterior do fêmur médio do macho: [0] ausente; [1] presente. Comprimento: 2; IC: 50; IR: 80.

21. Conjunto de cerdas fortes voltadas inseridas na metade basal do fêmur médio voltadas para o ápice deste, no macho: [0] ausente; [1] presente (fig. 6). Comprimento: 2; IC: 50; IR: 83.

22. Espinhos curtos no ápice da face A do fêmur médio do macho: [0] ausente; [1] presentes (fig. 6). Comprimento: 2; IC: 50; IR: 83.

23. Número de cerdas fortes na metade basal da face PV do fêmur médio do macho: [0] ausente; [1] 1 cerda; [2] 2 cerdas; [3] 3-4 cerdas; [4] 1 fileira. Comprimento: 10; IC: 40; IR: 62.

24. Forma da tíbia posterior do macho: [0] sem modificação (tíbia reta ou suavemente curvada); [1] com modificação (sinuosa ou muito curvada, fig. 7 e 8 respectivamente). Comprimento: 3; IC: 33; IR: 81.

25. Cerdas diferenciadas (finas com ápice curvo) na face PV da tíbia posterior do macho: [0] ausentes; [1] presentes (fig. 7). Comprimento: 2; IC: 50; IR:88.

26. Distribuição das cerdas finas com ápice curvo na face póstero-ventral da tíbia posterior do macho: [0] uma fileira em toda a face; [1] uma fileira nos dois terços basais; [2] um pincel mediano (fig. 7); [3] uma fileira nos dois terços apicais. Comprimento: 4; IC: 75; IR: 80.

27. Curvatura da porção distal do gonópodo (com relação à margem de inserção do hipândrio): [0] retilíneo (fig. 12); [1] curvada em direção ao hipândrio (fig. 13 e 14). Comprimento: 1; IC: 100; IR: 100.

28. Forma da margem interna inferior da placa cercal: [0] retilínea (fig. 15); [1] lobada (fig. 16). Comprimento: 6; IC: 16; IR: 28 .

29. Forma da margem inferior da placa cercal: [0] relitínea (fig. 15); [1] arredondada; [2] bilobada (fig. 16). Comprimento: 6; IC: 33; IR: 50.

30. Posição da porção mais alargada do quinto esternito do macho: [0] terço anterior (fig. 17); [1] terço médio; [2] dois terços posteriores; [3] terço posterior (fig. 18). Comprimento: 10; IC: 30; IR: 36.

31. Proporção entre o comprimento e a largura no quinto esternito do macho: [0] comprimento maior que a largura (fig. 17); [1] comprimento semelhante à largura (fig. 19); [2] comprimento menor que a largura (fig. 18). Comprimento: 5; IC: 40; IR: 72 
forte; face $\mathrm{P}$ com 2 cerdas, a primeira no nível médio e uma préapical; face PV com 3 cerdas a primeira no mesmo nível da mediana $\mathrm{P}$ e 1 pré-apical tão forte quanto a $\mathrm{PD} ; 2$ cerdas préapicais fracas posicionadas entre as pré-apicais $\mathrm{PD}, \mathrm{P}$ e PV. Fêmur posterior levemente curvo e levemente intumescido no terço apical; faces D e PD com pré-apicais inseridas no mesmo nível; faces P, PV e V sem cerdas fortes; face AV com uma fileira de 5 cerdas no terço basal e face AD com uma fileira de cerdas distribuídas em toda a face. Tíbia posterior (fig. 8) acentuadamente curva, com uma fileira de cerdas longas e finas no terço apical da face PD; uma fileira de cerdas fortes mais espaçadas no ápice na face $\mathrm{AD}$ e duas fileiras irregulares de finas em toda a face AV.

Quinto esternito tão longo quanto largo, mais alargado no terço médio (figura 19). Placa cercal com margem interna inferior retilínea e margem inferior bilobada (figura 20). Edeago como na figura 21.

Comprimento sem o abdome 5,5 $\mathrm{mm}$ (o abdome havia sido dissecado previamente). Asa 7,8 $\mathrm{mm}$.

Material-tipo. -Holótipo macho, etiquetado: "Perales/I.25" (etiqueta branca manuscrita); "Palpibracus univittatus Mll. nec Bgt=confusa Mll." (etiqueta branca manuscrita); "Holotipo" (etiqueta vermelha margeada de preta) [MNRJ]. Está em razoável estado; quetotaxia quase completa; abdome dissecado e acondicionado em um tubinho plástico com glicerina.

Parátipo macho, etiquetado "CHILE: Concepción/ Pinares/ Nov. 9.13-1970" (etiqueta branca); "Paratipo" (etiqueta verde, com linha preta no bordo) [MNRJ]. Faltam pernas anteriores e médias; quetotaxia bastante incompleta; abdome dissecado e acondicionado em um tubinho plástico com glicerina.

Considerações. Fêmea desconhecida.

Difere de P. separatus e P. similis pelo mesonoto marrom destas, de P. pilosus e por este apresentar listra dorsal estreita. Difere de $P$. similis, $P$. separatus e $P$. carvalhoi por estes não apresentarem espinhos curtos no ápice da face anterior do fêmur médio, sendo que os dois últimos também não apresentam esporão apical na coxa anterior. As espécies também diferem pela quetotaxia do tórax.

Etimologia. Nome dado em homenagem a Charles Darwin, coletor dos dois parátipos fêmeas de P. confusus (Malloch), nome novo de Darwinomyia univittata Malloch, espécie tipo de Darwinomyia Malloch, posteriormente sinonimizado com Palpibracus por Dalcy de Oliveira Albuquerque em 1951.

\section{Análise Cladística}

O gênero Palpibracus Rondani mostrou-se monofilético. A análise cladística resultou em apenas um cladograma, de comprimento 121, índice de consistência 42 e índice de retenção 72. Palpibracus apicalis Malloch foi transferida tentativamente para o gênero parafilético Psilochaeta (fig. 1), cuja análise não foi objetivo deste trabalho. Carvalho (1989a) já havia apontado que "P. apicalis está em uma posição isolada das demais [espécies de Palpibracus], por possuir caracteres mais plesiomórficos dentro do gênero".
A monofilia de Palpibracus Rondani foi suportada por dois caracteres referentes à coloração do tórax: mesonoto amarelo com uma listra dorsal mediana castanha (caráter $8_{1}$ ) e escutelo amarelo $\left(10_{1}\right)$. Dentre os Reinwardtiini, Correntosia bicolor Malloch também apresenta este padrão de coloração, porém este não foi utilizado nesta análise e difere de Palpibracus por apresentar macho dicóptico, olhos nus e cerdas catepisternais 2:1 (Carvalho 1989b). Este padrão ocorre na maioria das espécies, exceto em P. peruvianus, P. pilosus e $P$. similis que apresentam mesonoto dorsalmente marrom com borda lateral amarela $(8)$, mantendo o padrão amarelo do escutelo. Palpibracus lancifer apresenta coloração geral azul metálica $\left(8_{2}\right)$ diferindo do padrão geral do gênero e assemelhando-se as espécies dos gêneros próximos a Palpibracus. Apesar destas espécies não estarem dentro do padrão de cor sugerido como sinapomórfico para Palpibracus, $P$. lancifer, $P$. pilosus e $P$. similis apresentam esporão apical na coxa anterior (19. $)$ e, as duas primeiras, espinhos curtos no ápice da face anterior do fêmur médio (22), caracteres exclusivos do gênero Palpibracus. A monofilia de Palpibracus já havia sido sugerida por Carvalho (1989a) que afirmou ser este gênero bastante peculiar apesar de não indicar nenhuma sinapomorfia.

O cladograma aqui proposto apresenta Brachygasterina como grupo irmão de Palpibracus. Esta é a primeira vez que o relacionamento entre estes gêneros é testado pelo método filogenético uma vez que Carvalho (1989c) encontrou politomia para os gêneros de Reinwardtiini na única análise realizada utilizando estes gêneros. A relação entre Palpibracus e Brachygasterina é sustentada pela presença de uma cerda anterior no catepisterno $\left(13_{0}\right)$. O gênero Brachygasterina apresenta-se como um grupo monofilético sustentado pela presença de flagelômero fortemente dilatado $\left(5_{2}\right)$, caráter já apontado como sinapomorfia para o gênero por Carvalho (1989b) e por Carvalho \& Couri (2002).

A espécie Palpibracus veneris é a mais basal do gênero. Malloch (1934) já havia sugerido que esta espécie é aberrante no gênero. As demais espécies de Palpibracus encontram-se distribuídas em dois grandes clados reunidos pela presença de tíbia posterior sinuosa ou curvada no macho $\left(24_{1}\right)$, caráter que se apresenta no estado plesiomórfico no clado $P$. peruvianus $+P$. trivittatus e em $P$. spicatus $; 3$ cerdas posteriores no catepisterno (14 ${ }_{2}$ ), estado que ocorre também em Dalcyella veniseta e que em $P$. fasciculatus está no estado plesiomórfico.

O primeiro clado reúne ((P. albuquerquei (P. peruvianus, P. trivittatus)) (P. fasciculatus, P. nigriventris)) e é suportado pela presença de uma listra dorsal mediana larga $\left(9_{2}\right)$ no mesonoto. A presença de cerdas finas com ápice curvo, posicionadas como um pincel mediano $\left(26_{2}\right)$ na face posteroventral da tíbia posterior do macho, foi sinapomórfica para P. fasciculatus e P. nigriventris. A presença destas cerdas, posicionadas como uma fileira nos dois terços basais $\left(26_{1}\right)$, foi a sinapomorfia para $P$. peruvianus e $P$. trivittatus.

$O$ segundo clado foi suportado por duas sinapomorfias relativas à face anterior do fêmur médio do macho $\left(20_{1}, 22_{1}\right)$, e pela presença de esporão apical na coxa anterior $\left(19_{1}\right)$, caráter presente também em $P$. albuquerquei. Este clado apresenta $P$. 
spicatus e $P$. uvivittatus como grupo irmão do clado (P. lancifer (P. darwini ( $P$. chilensis, $P$. confusus $(P$. pilosus $(P$. similis $(P$. separatus, $P$. carvalhoi $)))))$ ) que é sustentado pela presença de um conjunto de cerdas fortes voltadas para o ápice do fêmur inseridas na metade basal na face ântero-dorsal do fêmur médio do macho $\left(21_{1}\right)$, exceto $P$. lancifer estas espécies apresentam catepímero ciliado $\left(15_{1}\right)$, estado que ocorre também em $P$. veneris. A presença dos caracteres $20_{1}, 21_{1}, 22_{1}$ em $P$. lancifer indicam que esta é uma espécie apical dentro do gênero apesar de apresentar caracteres de coloração semelhantes aos encontrados nos grupos externos mais próximos. O caráter 20 aparece no estado plesiomórfico em $(P$. pilosus ( $P$. similis ( $P$. separatus, $P$. carvalhoi $))$ ), o caráter 22 nas três últimas e o 21 em $P$. carvalhoi, a ausência de estados derivados é definidora desses clados que, por esta razão, tem pouco suporte. Apesar do clado formado por $P$. spicatus e $P$. univittatus ter sido sustentado apenas pela presença de cerda interfrontal na fêmea $\left(7_{1}\right)$, que em Palpibracus aparece também em $P$. separatus, a similaridade entre estas duas espécies já havia sido sugerida por Malloch (1934).

Agradecimentos. Á Márcia Souto Couri (MNRJ) e Gabriel Augusto Rodrigues de Melo (DZUP) pelas sugestões nas versões anteriores do manuscrito e a um revisor anônimo pelas sugestões no manuscrito final. Ao Conselho Nacional de Desenvolvimento Científico e Tecnológico-CNPq (EDGS, processo número 1310621/2002-6; CJBC, processo número 304148/2002-4) pela bolsa e auxílio concedidos. Esta é a contribuição número 1506 do Departamento de Zoologia da Universidade Federal do Paraná.

\section{REFERÊNCIAS}

Albuquerque, D. de O. 1951. Quinta nota sobre os tipos de Macquart (Diptera-Muscidae), existentes no Museu Nacional de História Natural de Paris e descrição de uma espécie nova, proveniente do Chile. Boletim do Museu Nacional do Rio de Janeiro (Zoologia) 105: 1-17.

Albuquerque, D. de O. 1979. Algumas notas sobre Muscidae neotropicais e descrição de um gênero e uma espécie nova (Diptera). Revista Brasileira de Biologia 39: 323-326.

Carvalho, C. J. B. de. 1989a. Revisão das espécies e posição sistemática de Palpibracus Rondani (Diptera, Muscidae). Revista Brasileira de Zoologia 6: 325-375.

Carvalho, C. J. B. de. 1989b. Revisão dos gêneros sul-americanos: Brachygasterina Malloch e Correntosia Malloch (Diptera, Muscidae). Revista Brasileira de Zoologia 6: 473-484.

Carvalho, C. J. B. de. 1989c. Classificação de Muscidae (Diptera): uma proposta através da análise cladística. Revista Brasileira de Zoologia 6: 627-648.

Carvalho, C. J. B. de; M. Bortolanza; M. C. C. Silva \& E. D. G. Soares. 2003. Distributional Pattern of the Neotropical Muscidae (Diptera), p. 263-274. In: J. J. Morrone \& J. Llorente B. (Edit.). Una perspectiva latinoamericana de la biogeografía. Ciudad del México: Universidad Autónoma do México. 307 p.

Carvalho, C. J. B. de \& M. S. Couri. 2002. Part I. Basal groups, p. 17132. In: C. J. B. de Carvalho (ed.). Muscidae (Diptera) of the Neotropical Region: taxonomy. Curitiba, Editora Universidade Federal do Paraná. 287 p.

Carvalho, C. J. B. de; M. S. Couri; A. C. Pont; D. Pamplona \& S. M. Lopes. 1993. Parte II. Muscidae, p.1-121. In: C. J. B. de Carvalho (ed.). A Catalogue of the Fanniidae and Muscidae (Diptera) of the Neotropical Region. São Paulo, Sociedade Brasileira de Entomologia. 201p.
Carvalho, C. J. B. de; M. S. Couri; A. C. Pont; D. Pamplona \& S. M. Lopes. 2005. A Catalogue of the Muscidae (Diptera) of the Neotropical Region. Zootaxa 860: 1-282.

Goloboff, P. 1993. NONA (NO NAME) ver. 2.0. Published by the author, INSUE fundación y Instituto Miguel Lillo, Tucumán.

Lopes, S. M. \& A. Khouri. 1996. Descrição de uma espécie nova de Palpibracus Rondani, 1863 do Chile (Diptera, Muscidae, Azelinae, Reiwardtiini). Ceres 43: 454-458.

Malloch, J. R. 1922. Exotique Muscaridae (Diptera). V. Annals and Magazines of Natural History (9) 9: 271-280.

Malloch, J. R. 1928. Exotique Muscaridae (Diptera). XXII. Annals and Magazines of Natural History (10) 2: 307-319.

Malloch, J. R. 1934. Muscidae. In: Diptera of Patagonia and South Chile. London, Part. 7 (2): 171-346.

McAlpine, J. F. 1981. Morphology and Terminology-adults p. 9-63. In: J. F. McAlpine; B. V. Peterson; G. E. Shewell.; H. J. Teskey; J. R. Vockeroth \& D. M. Wood (Edit.) Manual of Neartic Diptera., v. 1, Monograph 27. Otawa, Agriculture Canada Research Branch. $674 \mathrm{p}$.

Michelsen, V. 1991. Revision of the aberrant New World genus Coenosopsia (Diptera: Anthomyiidae), with discussion of anthomyiid relationships. Systematic Entomology 16: 85-104.

Nixon, K. C. \& J. M. Carpenter. 1993. On outgroups. Cladistics 9: 413-426.

Nixon, K.C. 1999. Winclada (BETA) ver. 0.9.9. Published by the author, Ithaca, Ny.

Page, R. 2001. NDE (NEXUS Data Editor For Windows) ver. 0.5.0. Published by the author, Glasgow, United Kingdom.

Pamplona, D. M. \& M. S. Couri. 2000. Espécie nova de Palpibracus Rondani (Diptera, Muscidae, Azelinae, Reiwardtiini). Boletim do Museu Nacional, Nova Série, Zoologia 431: 1-4.

Rondani, C. 1863. Diptera exotica revisa et annotata novis nonnullis descripis. Soliani, Modena, $99 \mathrm{pp}$.

Soares, E. D. G. \& C. J. B. de Carvalho. 2004. A new combination in Brachygasterina Macquart (Diptera, Muscidae). Revista Brasileira de Entomologia 48: 431.

\section{APÊNDICE}

Material examinado das espécies. As espécies do grupo externo estão indicadas nas subfamílias as quais pertencem, segundo classificação de Carvalho \& Couri (2002). As abreviaturas das instituições estão indicadas no texto.

Palpibracus albuquerquei Carvalho

Holótipo macho: etiqueta branca "Angol-Chile/ 16-Oct.1928 [manuscrito]"; etiqueta vermelha contornada com uma linha preta "Holotipo"; "Palpibracus albuquerquei" [manuscrito por C.J.B. de Carvalho] (MNRJ). Abdômen dissecado.

Palpibracus carvalhoi Lopes \& Khouri

Holótipo macho: etiqueta branca "Angol-Chile [digitado azul]/ 3Nov.1946 [manuscrito, 194 digitado]/J.Valenzuela"; etiqueta branca "Palpibracus/ carvalhoi Lop e Khouri [manuscrito]/ S.M.Lopes det. [digitado]"; etiqueta vermelha com linha preta "Holotipo". Parátipo fêmea. CHILE. Malleco: Angol, 1 fêmea, 14.VIII.1946 (5010 MNRJ), Mendoza col.; 1 fêmea, 21.VII.1946 (5007 MNRJ), Mendoza col.

Palpibracus chilensis (Bigot)

CHILE. Curicó. Rio Teno: 1 macho,14.II.1965 (MZSP), L.E. Peña col. Malleco. Angol: 3 fêmeas, 0106.XII.1970 (MZSP), T. Cekalovic col.

Palpibracus confusus (Malloch)

CHILE. Chiloé. Dalcahue: Ilha de Chiloé, 1 fêmea, I.1962 (MZSP), L.E. Peña col. Curicó. El Coigual: Cord. Curicó, 4 machos, I.1964 (MZSP), L.E. Peña col. Nuble. Las Trancas: Cord. Chillán, 1 fêmea, 24.III.1968 (MZSP).

Palpibracus fasciculatus (Malloch)

CHILE. Chiloé. Dalcahue: Ilha de Chiloé, 1 fêmea, I.1962 (MZSP), L.E. Peña col. 
Palpibracus lancifer (Malloch)

CHILE. Osorno. Putricahue: 1 fêmea, II. 1967 (MZSP), L.E. Peña col.

Palpibracus nigriventris (Malloch)

CHILE. Cautin. Lago Galletue: Cord. Lonquimay, 1 fêmea, I.1962 (MZSP), L.E. Peña col. Chiloé. Dalcahue: Ilha de Chiloé, 35 fêmeas, 15 machos, I.1962 (MZSP), L.E. Peña col. Curicó. El Coigual: Cord. Curicó, 1 macho, I.1964 (MZSP), L.E. Peña col. Llanquihue. Hornohuinco: N. de Correntoso, 4 fêmeas, 2 machos, III.1968 (MZSP), L.E. Peña col.; 1 macho, XII.1968 (MZSP), L.E. Peña col.

Palpibracus peruvianus (Malloch)

CHILE. Curicó. Rio Teno: 1 macho, 14.II.1965 (MZSP), L.E. Peña col.

Palpibracus pilosus (Macquart)

CHILE. Magallanes. Punta Arenas: 2 fêmeas, 1 macho, 09-15.I.1966 (USNM), Flint \& Cekalovic col.

Palpibracus separatus (Malloch)

CHILE. Linares. Cord. Parral: Fdo. Macho, 1 macho, 20.XI.1964 (MZSP), L.E. Peña col. Osorno. Putricahue: 2 fêmeas, II. 1967 (MZSP), L.E. Peña col. Santiago. Las Condes: 1 macho, XI.1963 (MZSP), L.E. Peña col.

Palpibracus similis (Malloch)

CHILE. Nuble. Las Trancas: Cord. Chillán, 1 macho, II.1969 (DZUP), L.E. Peña col.

Palpibracus spicatus (Malloch)

CHILE. Chiloé. Dalcahue: Ilha de Chiloé, 14 fêmeas, 1 macho, I.1962 (MZSP), L.E. Peña col.; 4 fêmeas,1 macho, IV.1968 (MZSP), L.E. Peña col. Curicó. El Coigual: Cord. Curicó, 1 fêmea, I.1964 (MZSP), L.E. Peña col. Osorno. Putricahue: 2 fêmeas, II.1967 (MZSP), L.E. Peña col.

Palpibracus trivittatus (Malloch)

CHILE. Linares.Cord. Parral: Fdo. Macho, 1 fêmea, 3 machos, 20.XI.1964 (MZSP), L.E. Peña col.

Palpibracus univittatus (Bigot)

CHILE. Chiloé. Dalcahue: Ilha de Chiloé, 1 fêmea, I.1962 (MZSP), L.E. Peña col. Osorno. Putricahue: 2 machos, II.1967 (MZSP), L.E. Peña col.

\section{Palpibracus veneris (Bigot)}

CHILE. Nuble. Las Trancas, Refúgio Andino, Volcán de Chillán, 2 machos, 1 fêmea, I.1970 (MZSP), L.E. Peña col.

Delia platura (Meigen) (Anthomyiidae)

BRASIL. Paraná. Colombo: Empresa Brasileira de Pesquisa Agropecuária (EMBRAPA, Br476 km 20), 1 fêmea, 3 machos, 02.XI.1986 (DZUP), PROFAUPAR (lâmpada); 3 fêmeas, 1 macho, 03.XI.1986 (DZUP), PROFAUPAR (lâmpada). Guarapuava: Estação de Águas Santa Clara, 3 fêmeas, 02.XI.1986 (DZUP), PROFAUPAR (lâmpada); 1 fêmea, 04.XI.1986 (DZUP), PROFAUPAR (lâmpada); 2 machos, 31.X.1986 (DZUP), PROFAUPAR (lâmpada); 2 machos, 1.XI.1986 (DZUP), PROFAUPAR (lâmpada).

Ophyra albuquerquei Lopes, 1985 (Muscidae, Azeliinae, Azeliini) Material examinado. BRASIL. Rio Grande Do Sul. Pelotas: 15 fêmeas, 20 machos, II.2001 (DZUP), R.F. Krüger col.

Brachygasterina major Malloch, 1934 (Muscidae, Azeliinae, Reinwardtiini)

CHILE. Cord. Chillán. Las Cabras: 1 fêmea, XI.1964 (MZSP) L. E. Penã col. Cord. Lonquimay. Lago Galletue: 1 macho, I. 1962 (MZSP) L. E. Peña col.Tolhuaca. Termas: 4 fêmeas, 20.I.1950 (MZSP) L. E. Penã col.
Brachygasterina valdiviensis (Pamplona \& Couri) (Muscidae, Azeliinae, Reinwardtiini)

Holótipo fêmea: "CHILE, Valdivia, $39^{\circ} 48^{\prime}$ "Sur, $73^{\circ} 15^{\prime}$ W, Recolector [Luis Figueroa], R-R-Sm, 29/VIII/97 (MNRJ)". Paratipo-fêmea. CHILE, Valdivia, 39⒋" Sur, 7315" W, Recolector [Luis Figueroa] P-S-Sol, 25/VIII/97" (MNRJ/7719); P-S-Som, 10/VIII/97(MNRJ/7717).

Dalcyella veniseta Carvalho, 1989 (Muscidae, Azeliinae, Reinwardtiini) CHILE: Santiago, Rincón El Árbol, Aculeo, 2 fêmea, 3 machos, X.1969 (MZSP), L. E. Peña col.

Muscina stabulans Fallén (Muscidae, Azeliinae, Reinwardtiini) BRASIL. Paraná. Estrada do Cerne (km11 PR_BRASIL): 1 fêmea, 12.XI.1975/R.fora (DZUP), A. Imbiriba col. Curitiba: 2 fêmeas, 2 machos, 20.X.1980 (DZUP), (pupa em wheat decayed), C. J. B. de Carvalho col; Uberaba, 1 fêmea, 30.IV.1975 (DZUP), A. Imbiriba col. CHILE. Valdivia. (1 fêmea, DZUP), L. Figueroa Roa.

Psilochaeta apicalis (Malloch) comb. nov. (Muscidae, Azeliinae, Reinwardtiini)

Parátipo fêmea. ARGENTINA. Bariloche. Rio Negro. 2 fêmeas, AgrNov 1926 R\&E Shannon col. (49768 USNM); ibidem (5004 MNRJ).

Psilochaeta chalybea (Wiedemann) (Muscidae, Azeliinae, Reinwardtiini) CHILE. Concepción. Pinares: 4 fêmeas, 5 machos, 09-13.XI.1970; 1 macho, 20.IX.1970 (MZSP), T. Cekalovik col. Santiago. 3 fêmeas, 7 machos, 19.X. 1963 (MZSP), L. E. Peña col. Valparaíso. Laguna Verde: 1 macho, X.1969 (MZSP); 1 fêmea, 5.X.1969 (MZSP), L. E. Peña col. Psilochaeta chlorogaster (Wiedemann) (Muscidae, Azeliinae, Reinwardtiini)

CHILE. Concepción. Pinares: 4 fêmeas, 5 machos, 09-13.XI.1970 (DZUP); 3 fêmeas, 2 machos, 20.IX.1970 (MZSP) T. Cekalovik col. Malleco. Angol: 1 fêmea, 1 macho, 16-21.XI.1970 (DZUP); 1 macho, 23-28.XI.1970 (DZUP); 2 fêmeas, 2 machos, 01-06.X.1970 (DZUP) T. Cekalovik col.

Psilochaeta pampiana (Shannon \& Del Ponte) (Muscidae, Azeliinae, Reinwardtiini)

BRASIL. Minas Gerais. Ouro Preto: 1 macho, VIII.1969 (MZSP) F. C do Val col. Paraná. Curitiba: 1 fêmea, 2 machos, 19.X.1982 (DZUP) R. Misiuta col.; 2 fêmeas, 26.VI.1984 (DZUP); 1 fêmea, 28-29.VI.1984 (DZUP) R. Zonta \&M. Santos col. São Paulo. São Paulo (Ipiranga): 8 fêmeas, VII.1970 (MZSP) N. Papavero col. Barueri: 1 fêmea, 03.II.1962 (MZSP); 1 fêmea, 04.XII.1965 (MZSP); 1 macho, 06.XII.1965 (MZSP); 1 macho, 10.XII.1965 (MZSP); 1 fêmea, 1 macho, 20.XII.1965 (MZSP) K. Lenko col.

Psilochaeta violescens (Dodge) (Muscidae, Azeliinae, Reinwardtiini) CHILE. Concepción. Pinares: 2 machos, X.1970 (MZSP); 4 fêmeas, 3 machos, 20.IX.1970 (MZSP) T. Cekalovik col. Coquimbo. Pto. Oscuro: 4 fêmeas, 4 machos, X.1961 (MZSP) L. E. Peña col. Santiago. 6 fêmeas, 8 machos, 19.X.1963 (MZSP) L. E. Peña col.

Synthesiomyia nudiseta Brauer \& Bergenstamm (Muscidae, Azeliinae, Reinwardtiini)

BRASIL. Bahia. Anajé, 1 macho, 15-24.V.1975 (DZUP) C. \& P. Elias col. Paraná. Estrada do Cerne (km11_PR_BRASIL), 1 fêmea, 20.III.1976/R.fora (DZUP), A. Imbiriba col. Guaratuba, 1 macho, 07.XI.1965 (DZUP) C. Dipterologia; Curitiba: 1 macho, 16.V.1981 (DZUP), C. B. Jesus (Mata, Fígado); Santa Felicidade, 1 fêmea, 10.III.1976 (DZUP), A. Imbiriba; Uberaba, 1 fêmea, 17.III.1976 (DZUP), A. Imbiriba; Uberaba, 1 macho, 7.IV.1976 (DZUP), A. Imbiriba; Uberaba, 1 fềmea, 1 macho, 25.II.1976 (DZUP), A. Imbiriba.

Recebido em 14.VII.2004; aceito em 28.IV.2005 